\title{
p38MAPK mediates IL-1-induced down-regulation of aggrecan gene expression in human chondrocytes
}

\author{
JÜRGEN RADONS ${ }^{1}$, ANJA KATRIN BOSSERHOFF ${ }^{2}$, SUSANNE GRÄSSEL ${ }^{3}$, \\ WERNER FALK ${ }^{4}$ and THOMAS E.O. SCHUBERT ${ }^{2}$ \\ ${ }^{1}$ Abteilung Hämatologie und Internistische Onkologie, ${ }^{2}$ Institut für Pathologie, Universität Regensburg, \\ D-93053 Regensburg; ${ }^{3}$ Abteilung Experimentelle Orthopädie, Klinik und Poliklinik für Orthopädie \\ der Universität Regensburg, D-93077 Bad Abbach; ${ }^{4}$ Klinik und Poliklinik für Innere Medizin I, \\ Universität Regensburg, D-93042 Regensburg, Germany
}

Received October 26, 2005; Accepted December 19, 2005

\begin{abstract}
The pleiotropic cytokine interleukin 1 (IL-1) is considered to be the principal inducer of mediators of cartilage degradation in both, osteoarthritis (OA) and rheumatoid arthritis (RA). IL-1 activates numerous signaling pathways involved in cartilage destruction and dedifferentiation of chondrocytes. In this study, we analyzed expression and functional effects of IL-1 in human chondrocytes. We found an IL-1-induced reduction in the expression of the cartilage specific proteoglycan aggrecan as an indicator for the IL-1mediated dedifferentiation of chondrocytes. To block the IL-1induced signaling pathways specifically, we incubated human chondrocytes and cartilage explants with IL-1 in the presence of different signal transduction inhibitors and analyzed their effect on aggrecan mRNA expression and IL-6 secretion. IL-6 has been found to act synergistically in the IL-1-induced suppression of the proteoglycan synthesis in chondrocytes. Our results led to the identification of p38MAPK and/or PI3K/JNK as being crucial for IL-1-induced IL-6 secretion by chondrocytes. IL-1-induced down-regulation of aggrecan expression was found to be mediated by p38MAPK and/or ERK1/2. The identification and characterization of these signaling pathways will enable us to develop new modulation strategies for therapeutic use in inflammatory joint diseases.
\end{abstract}

\section{Introduction}

Cartilage plays a crucial role in maintaining joint functions, since it acts as a shock absorber during joint loading and motion. Extracellular matrix molecules including aggrecan

Correspondence to: Dr Jürgen Radons, Abteilung Hämatologie und Internistische Onkologie, Universitätsklinikum Regensburg, D-93053 Regensburg, Germany

E-mail: juergen.radons@klinik.uni-regensburg.de

Key words: chondrocytes, IL-1, IL-6, p38MAPK, signal transduction, aggrecan, PI3K, JNK, ERK1/2 and collagen type II provide the structural basis for this shock-absorbing function. Chronic joint inflammation and concurrent joint erosion and destruction are the main features of inflammatory joint diseases leading to a loss of joint function as a result of proteolytic cleavage of matrix molecules such as collagen type II and aggrecan (for review see refs. 1,2).

Numerous studies based on various animal models of arthritis have investigated the relative importance of IL-1 in the process of inflammation and destruction (3). IL-1 plays a pivotal role in the destructive processes of arthritis, presumably due to its potent inhibitory effect on tissue repair. One further explanation for its deleterious effect in arthritis might be the induction of chondrocyte dedifferentiation. IL-1 is a pleiotropic cytokine and is considered to be the principal inducer of cartilage-degrading mediators in both, osteoarthritis (OA) and rheumatoid arthritis (RA) (1). The contribution of IL-1 to arthritis and cartilage degradation is supported by the finding that the synovial fluid of arthritis patients contains elevated levels of IL-1 (4). IL-1 is produced by cells in the arthritic joint including chondrocytes, fibroblasts, macrophages and bone-lining cells. The two agonists, IL- $1 \alpha$ and IL-1ß bind to a specific plasma membrane receptor, the IL-1 receptor type I (IL-1RI). A third ligand, IL-1Ra, of which three intracellular isoforms exist, binds to IL-1RI and acts as a true receptor antagonist. Signaling via IL-1RI requires expression of the co-receptor molecule, IL-1 receptor accessory protein (IL1RAcP) (5) that has been found as being essential for IL-1 signaling (6-8). A second receptor, the IL-1 receptor type II (IL-1RII), is thought to act as a decoy receptor serving as a ligand sink and competing for IL-1 and IL-1RAcP with IL1RI $(9,10)$. After binding to IL-1RI, IL-1 activates numerous signaling pathways culminating in the activation of $\mathrm{NF}-\kappa \mathrm{B}$, mitogen-activated protein kinase (MAPK) p38, extracellular signal-regulated kinases p42/p44 (ERK1/2), c-Jun N-terminal kinase (JNK) and phosphatidylinositol 3-kinase (PI3K) $(11,12)$. Signaling via p38MAPK and JNK appears to be the most relevant mechanism for the expression of IL-1-induced catabolic mediators in arthritis as it is involved in the induction of several matrix metalloproteinases degrading proteglycans and collagen type II in cartilage $(13,14)$. The cytokine also inhibits the synthesis of new matrix proteins in cartilage 
including aggrecan and the proliferation of chondrocytes which are necessary for cartilage repair $(15,16)$. In this context, an essential synergistical role was claimed for IL-6 in the IL-1-induced suppression of proteoglycan synthesis (17). It is generally accepted that IL-1 is a potent inducer of IL-6 production in primary cells and cell lines of articular tissues (18-20).

In order to eliminate negative effects of IL-1 on cartilage, we aimed to analyze signal transduction pathways potentially affecting cartilage integrity and chondrocyte differentiation. Our data provide evidence that specific inhibition of defined pathways reduces IL-1-mediated chondrocytic dedifferentiation.

\section{Materials and methods}

Preparation of cartilage explants and human chondrocytes. For the study of healthy tissue, human cartilage was taken from the humeral heads of corpses during autopsy within $16 \mathrm{~h}$ of death after obtaining approval from the local ethics committee. Cartilage from seven donors (all male; mean \pm SEM age $42 \pm 2.8$ years) without any evidence of macroscopic articular degeneration was used for explant culture. Intact cartilage was cut into $200 \mathrm{mg}$ slices and incubated at $37^{\circ} \mathrm{C}$ and $10 \% \mathrm{CO}_{2}$ in Ham's F-12/DMEM (1:1) medium supplemented with $1 \mu \mathrm{g} / \mathrm{ml}$ amphotericine B (Bristol-Myers Scribb, München, Germany), FCS, vitamins and antibiotics for the indicated time in the presence or absence of recombinant $(r)$ human (h) IL-1 $\alpha$ after preincubation with or without distinct signaling inhibitors. Chondrocytes were prepared from normal cartilage samples by enzymatic digestion essentially as previously described (21). Isolated chondrocytes were plated in $75-\mathrm{cm}^{2}$ tissue culture flasks in Ham's F-12/DMEM (1:1) supplemented with $10 \%$ FCS, MEM vitamins, $100 \mu \mathrm{g} / \mathrm{ml}$ streptomycin, and $100 \mathrm{U} / \mathrm{ml}$ penicillin and cultured at $37^{\circ} \mathrm{C}$ in humidified air with $10 \% \mathrm{CO}_{2}$ for a maximum of two passages.

Cell culture. Peripheral blood mononuclear cells (PBMNC) were separated by leukapheresis of healthy donors followed by density gradient centrifugation over Ficoll/Hypaque. Isolated PBMNC were cultured in RPMI-1640 medium (PAN Biotech $\mathrm{GmbH}$, Aidenbach, Germany) in the presence of $2 \%$ human pooled AB-group serum and $5 \times 10^{-8} \mathrm{M} B$-mercaptoethanol supplemented with vitamins, sodium pyruvate, and nonessential amino acids (all from PAA Laboratories, Linz, Austria). For stimulation, cells were co-cultered with $100 \mathrm{ng} /$ $\mathrm{ml}$ LPS, $20 \mathrm{ng} / \mathrm{ml}$ PMA and $10 \mathrm{nM}$ ionomycin (all from Sigma-Aldrich, Deisenhofen, Germany). Human chondrosarcoma cells SW1353 were cultured in Ham's F-12/DMEM (1:1) supplemented with $10 \%$ FCS, MEM vitamins, $100 \mu \mathrm{g} / \mathrm{ml}$ streptomycin, and $100 \mathrm{U} / \mathrm{ml}$ penicillin and cultured at $37^{\circ} \mathrm{C}$ in humidified air with $10 \% \mathrm{CO}_{2}$. Mouse thymoma cells EL4/5D3 were cultured in RPMI-1640 medium containing $2 \mathrm{mM}$ glutamine, $10 \% \mathrm{FCS}$, and $30 \mu \mathrm{M} \beta$-mercaptoethanol at $37^{\circ} \mathrm{C}$ in humidified air with $5 \% \mathrm{CO}_{2}$. rhIL-1 $\alpha$ was purchased from PAN Biotech GmbH. The c-Jun N-terminal kinase (JNK) inhibitor SP600125 was obtained from Biomol GmbH (Hamburg, Germany). Inhibitors for ERK1/2 (PD98059) and p38MAPK (SB203580) were provided by Calbiochem (Darmstadt, Germany). The PI3K inhibitor LY294002 was obtained from New England Biolabs GmbH (Frankfurt,
Germany). Stock solutions were prepared in DMSO and stored at $-20^{\circ} \mathrm{C}$. Serial dilutions were made in culture medium containing FCS. For stimulation, $6.5 \times 10^{4}$ cells (SW1353 and primary chondrocytes) were seeded in 6-well plates until a confluency of $80 \%$ was reached. Afterwards, cells were stimulated with $10 \mathrm{U} / \mathrm{ml}$ rhIL- $1 \alpha$ for $24-48 \mathrm{~h}$. Inhibitors were added $2 \mathrm{~h}$ prior to IL-1 incubation; the DMSO concentration within each sample including negative controls was adjusted equally. Functionality of the inhibitors was confirmed by analyzing the inhibitory capacities of PD98059, SB203580, and SP600125 on IL-2 secretion by mouse thymoma cells EL4/ $5 \mathrm{D} 3$ in a concentration-dependent manner. From these studies, we calculated the following $\mathrm{IC}_{50}$ values: PD98059 $(50 \mu \mathrm{M})$, SB203580 $(37.5 \mu \mathrm{M})$, SP600125 $(25 \mu \mathrm{M})$. Functionality of the PI3K inhibitor LY294002 was evaluated by Western blotting using anti-phospho-Akt antibodies (New England Biolabs $\mathrm{GmbH}$ ) and lysates from human melanoma and SW1353 cells. None of the inhibitors displayed any cytotoxic effect at the concentrations used.

RNA extraction. Human cartilage explants were frozen in liquid $\mathrm{N}_{2}$ and ground in a laboratory ball mill (Mikro-Dismembrator S; B. Braun, Melsungen, Germany). Total cellular RNA was isolated from different sources using the RNeasy ${ }^{\circledR}$ spin column purification kit (Qiagen, Hilden, Germany). RNA concentrations were measured using the RiboGreen ${ }^{\circledR}$ RNA quantitation kit (Molecular Probes, Leiden, The Netherlands).

Reverse transcription and semi-quantitative PCR. Reverse transcription (RT) was performed with $750 \mathrm{ng}$ of total cellular RNA using the SuperScript ${ }^{\mathrm{TM}}$ II RNase $\mathrm{H}^{-}$reverse transcriptase (Invitrogen, Karlsruhe, Germany) in a total volume of $20 \mu 1$. After an initial heat inactivation for $10 \mathrm{~min}$ at $70^{\circ} \mathrm{C}$, firststrand cDNA synthesis was carried out with $500 \mathrm{ng}$ random primer and $200 \mathrm{U}$ SuperScript II for $50 \mathrm{~min}$ at $37^{\circ} \mathrm{C}$ followed by heat inactivation at $70^{\circ} \mathrm{C}$ for $10 \mathrm{~min}$. PCR was performed in a total volume of $25 \mu \mathrm{l}$ using $50 \mathrm{pmol}$ of forward and reverse primers as given in Table I. After activating polymerase for $15 \mathrm{~min}$ at $95^{\circ} \mathrm{C}$, the cDNA was amplified by $25-35$ cycles of $95^{\circ} \mathrm{C}$ for $1 \mathrm{~min}, 55-65^{\circ} \mathrm{C}$ for $1 \mathrm{~min}$, and $72^{\circ} \mathrm{C}$ for $1 \mathrm{~min}$ using the HotStarTaq ${ }^{\mathrm{TM}}$ Master Mix kit (Qiagen) followed by a final extension period of $10 \mathrm{~min}$ at $72^{\circ} \mathrm{C}$. IL-1RI cDNA was specifically amplified using $0.6 \mathrm{U}$ of HotStarTaq ${ }^{\mathrm{TM}}$ DNA polymerase (Qiagen) in the presence of $3 \mathrm{mM} \mathrm{MgCl} 2$ under the conditions mentioned above. In contrast, aggrecan cDNA was amplified with $1.5 \mathrm{mM} \mathrm{MgCl}_{2}$ and a 5-min extension period at $72^{\circ} \mathrm{C}$. PCR products were resolved on $1.2 \%$ agarose gels and visualized by staining with ethidium bromide and UV transillumination.

Analysis of mRNA expression by quantitative PCR. Quantitative real-time PCR was performed using a LightCycler (Roche, Mannheim, Germany). $2 \mu$ l cDNA template, $2 \mu 125 \mathrm{mM}$ $\mathrm{MgCl}_{2}, 0.5 \mu \mathrm{M}$ of forward and reverse primers (Table I) and $2 \mu 1$ of SybrGreen LightCycler Mix in a total of $20 \mu 1$ were applied to the following PCR program: $30 \mathrm{sec} 95^{\circ} \mathrm{C}$ (initial denaturation); $20^{\circ} \mathrm{C} / \mathrm{sec}$ temperature transition rate up to $95^{\circ} \mathrm{C}$ for $15 \mathrm{sec}, 3 \sec 65^{\circ} \mathrm{C}, 5 \sec 72^{\circ} \mathrm{C}, 81^{\circ} \mathrm{C}$ acquisition mode single, repeated for 40 times (amplification). The PCR was evaluated by melting curve analysis and checking the PCR 
Table I. Primer sets, annealing temperature, and cycle number used for polymerase chain reaction.

\begin{tabular}{|c|c|c|c|c|}
\hline Gene & Primers & $\begin{array}{c}\text { Annealing } \\
\text { temperature }\left({ }^{\circ} \mathrm{C}\right)\end{array}$ & $\begin{array}{c}\text { RT-PCR } \\
\text { product (bp) }\end{array}$ & $\begin{array}{l}\text { No. of } \\
\text { cycles }\end{array}$ \\
\hline IL-1 $\alpha$ & $\begin{array}{l}\text { f: CCC AAG ATG AAG ACC AAC CAG TGC TG } \\
\text { r: CCC CCT GCC AAG CAC ACC CAG }\end{array}$ & 58 & 187 & 35 \\
\hline IL-1ß & $\begin{array}{l}\text { f: GGA GGG ACC AAA GGC GGC CAG GAT AT } \\
\text { r: CGT GGT TTC TGT CAG GCG GGC TTT A }\end{array}$ & 65 & 339 & 35 \\
\hline IL-1RI & $\begin{array}{l}\text { f: ATG CAT CCT ACA CAT ACT TGG } \\
\text { r: CAT CTG AAG CTT TTA TTG GG }\end{array}$ & 57 & 555 & 35 \\
\hline IL-1RAcP & $\begin{array}{l}\text { f: GCC AGC CAT CGG GCA TTA ATT GAT T } \\
\text { r: TTG GCA AGA GAA TGG TCC TTT GGT GAC }\end{array}$ & 57 & 523 & 35 \\
\hline sIL-1Ra & $\begin{array}{l}\text { f: GGC CTC CGC AGT CAC CTA ATC ACT CT } \\
\text { r: CTT CGT CAG GCA TAT TGG }\end{array}$ & 50 & 478 & 35 \\
\hline icIL-1Ra1 & $\begin{array}{l}\text { f: CAG AAG ACC TCC TGT CCT ATG } \\
\text { r: CTT CGT CAG GCA TAT TGG }\end{array}$ & 52 & 641 & 35 \\
\hline icIL-1Ra2 & $\begin{array}{l}\text { f: GCT GAC TTG TAT GAA GAA GGA GGT GG } \\
\text { r: CTT CGT CAG GCA TAT TGG }\end{array}$ & 52 & 493 & 35 \\
\hline icIL-1Ra3 & $\begin{array}{l}\text { f: ATC ATC AAA GCC AAG AAG GC } \\
\text { r: CTT CGT CAG GCA TAT TGG }\end{array}$ & 53 & 583 & 35 \\
\hline IL-1RII & $\begin{array}{l}\text { f: CCG GCA CAC CCT TAA CCA CCA TGC T } \\
\text { r: CCA AAA CCA AGA AGG CCA GTG AAA GTG }\end{array}$ & 65 & 303 & 35 \\
\hline Aggrecan & $\begin{array}{l}\text { f: TGA GGA GGG CTG GAA CAA GTA CC } \\
\text { r: GGA GGT GGT AAT TGC AGG GAA CA }\end{array}$ & 56 & 350 & 30 \\
\hline GAPDH & $\begin{array}{l}\text { f: TTA GCA CCC CTG GCC AAG G } \\
\text { r: CTT ACT CCT TGG AGG CCA TG }\end{array}$ & 57 & 540 & 25 \\
\hline
\end{tabular}

f, forward; $r$, reverse.

products on $1.0 \%$ agarose gels. Expression levels were calculated using the LightCycler software (Roche) and standardized to GAPDH.

Cytokine assays. Concentrations of IL-6 in the cell culture supernatants were evaluated by sandwich-ELISA (BD Biosciences, Erembodegem, Belgium) measuring serial dilutions of supernatants from IL-1-treated or -untreated cells in the presence or absence of certain inhibitors. IL-2 secretion by mouse thymoma EL4/5D3 cells was quantified as previously described (7).

Flow cytometry. For flow cytometry analysis, $1.5-2 \times 10^{5}$ cells were stained for $1 \mathrm{~h}$ at $0^{\circ} \mathrm{C}$ in the dark, either with $1 \mu \mathrm{g} / \mathrm{ml}$ of biotinylated anti-IL-1RAcP or unconjugated anti-IL-1RI (both from R\&D Systems, Wiesbaden, Germany) or anti-IL-1RAcP (ProSci Inc., Poway, CA, USA). After washing, cells were incubated with $5 \mu 1$ of biotinylated anti-rabbit IgG (Dako, Glostrup, Denmark) as secondary antibody for a further $1 \mathrm{~h}$ followed by a final 1-h incubation in the presence of $10 \mu \mathrm{l}$ FITC-labelled avidin (R\&D Systems). In the case of bio- tinylated IL-1RAcP, cells were directly stained with FITCconjugated avidin. Surface expression was then measured in comparison to an isotype-matched control sample using a Coulter $^{\circledR}$ EPICS $^{\mathrm{TM}}$ XL flow cytometer (Beckman Coulter $\mathrm{GmbH}$, Krefeld, Germany). The fluorescence histograms were generated using gated data.

Statistical analysis. Statistical differences between mean values were analyzed using the two-sided Student's t-test. Differences were considered as significant for $\mathrm{p}<0.05$.

\section{Results}

Expression of IL-1 isoforms and receptors in human chondrocytes. Firstly, we analyzed human primary chondrocytes from healthy donors and the human chondrosarcoma cell line SW1353 with regard to the expression of several components of the IL-1 signaling pathway. As a positive control, we used stimulated human PBMNC known to express several IL-1 family members. Using semi-quantitative RT-PCR, constitutive expression of IL-1RI, IL-1RAcP, and IL-1ß was found. In 

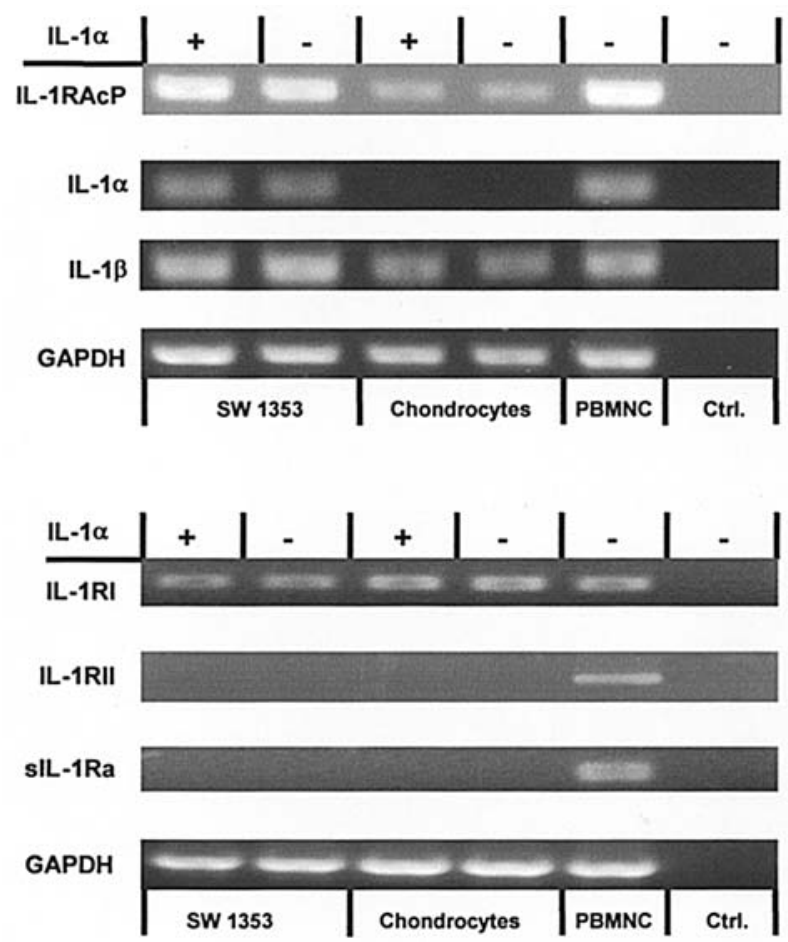

Figure 1. Expression of several members of the IL-1 family in human chondrocytes and PBMNC. Human chondrosarcoma cells SW1353 and human primary chondrocytes from healthy donors were cultured in the presence or absence of $10 \mathrm{U} / \mathrm{ml} \mathrm{rhIL-1} \alpha$ for $24 \mathrm{~h}$, whereas human PBMNC were costimulated with $100 \mathrm{ng} / \mathrm{ml}$ LPS, $20 \mathrm{ng} / \mathrm{ml} \mathrm{PMA}$, and $10 \mathrm{nM}$ ionomycin for $4 \mathrm{~h}$. Total RNA was prepared and reverse transcribed followed by semiquantitative RT-PCR and agarose gel-electrophoresis including the negative control (Ctrl.).

contrast to SW1353 cells, human primary chondrocytes did not express any detectable mRNA of IL- $1 \alpha$, neither constitutively nor after IL-1 stimulation. Moreover, no mRNA of the antiinflammatory components IL-1RII and soluble IL-1Ra was detectable in both, SW1353 and primary chondrocytes in the presence or absence of IL-1 (Fig. 1). Accordingly, neither variant of two intracellular isoforms of IL-1Ra (icIL-1Ra1 and icIL-1Ra2) could be detected (data not shown). We additionally analyzed IL-1RI and IL-1RAcP on the protein level by flow cytometry and observed a weak surface display of both receptor chains in SW1353 cells. A surface display of the same order of magnitude was also found in the IL-1 highly responsive mouse thymoma cell line EL4/5D3 (Fig. 2) that was reported to carry high numbers of IL-1 receptors type I in comparison to other cell types (6). Nevertheless, a low number of IL-1RI molecules $(<10)$ is sufficient for initiation of the IL-1 signaling cascade providing complete IL-1 responsiveness (22).

Effect of IL-1 on chondrocytes. As published previously, IL-1 is expected to have a dedifferentiating effect on chondrocytes $(23,24)$. To analyze whether this effect is repressable, we treated SW1353 cells with IL-1 in the presence or absence of inhibitors of the ERK1/2 (PD98059), p38MAPK (SB203580), PI3K (LY294002) or JNK pathway (SP600125) and analyzed changes in the expression level of aggrecan by quantitative RT-PCR. Aggrecan is known to be a specific marker of

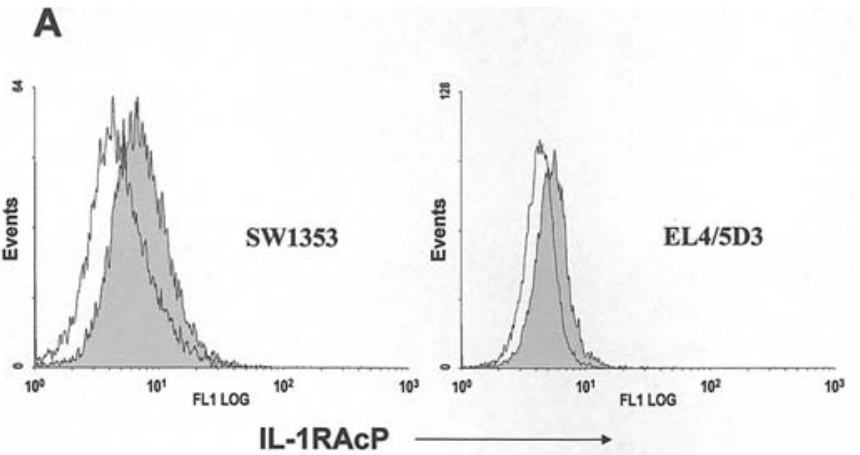

B

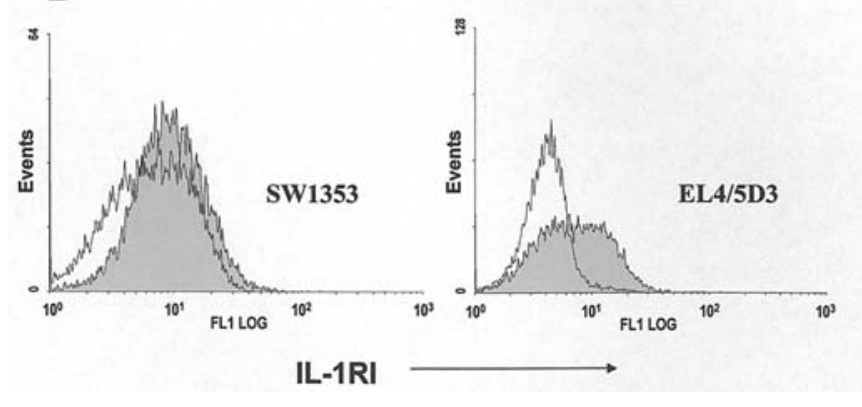

Figure 2. Flow cytometry analysis of IL-1RI and IL-1RAcP. Human chondrosarcoma cells SW1353 and mouse thymoma cells EL4/5D3 were stained with anti-IL-1RAcP (A) or anti-IL-1RI (B), and analyzed for surface expression of the corresponding antigens by flow cytometry. The white histogram represents the isotype-matched control; the grey histogram represents IL-1RI and IL-1RAcP-positive cells, respectively.

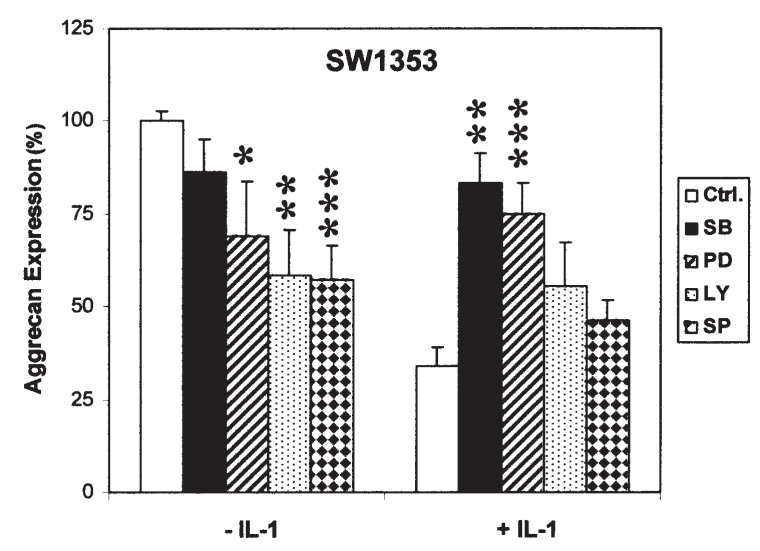

Figure 3. Effect of IL-1 on aggrecan expression in human chondrosarcoma cells. SW1353 cells were stimulated with or without $10 \mathrm{U} / \mathrm{ml} \mathrm{rhIL}-1 \alpha$ in the presence or absence of $10 \mu \mathrm{M}$ SP600125 (SP), $10 \mu \mathrm{M}$ SB203580 (SB), $10 \mu \mathrm{M}$ PD98059 (PD), and $50 \mu$ M LY294002 (LY), respectively. Aggrecan mRNA expression was analyzed after $48 \mathrm{~h}$ by quantitative real-time PCR. Aggrecan expression of the untreated controls was set as $100 \%$. Data represent means \pm SEM from six separate experiments performed in triplicates. ${ }^{*} \mathrm{p}<0.05 ;{ }^{* *} \mathrm{p}<0.01$; ${ }^{* * *} \mathrm{p}<0.001$ compared to control in each group.

differentiated chondrocytes (25). As demonstrated in Fig. 3, IL-1 induced a strong down-regulation of the aggrecan expression of approximately 65\% compared to untreated controls. Only inhibition of p38MAPK by SB203580 and inhibition of ERK1/2 by PD98059 led to an almost complete preservation of the marker molecule, whereas inhibition of 


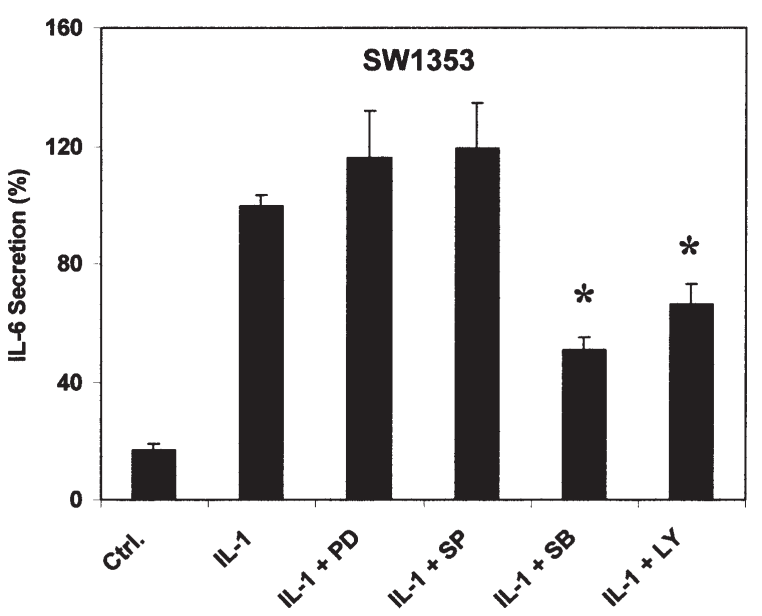

Figure 4. p38MAPK and PI3K are crucial signaling pathways involved in IL-1-induced IL-6 secretion in human chondrosarcoma cells. SW1353 cells were stimulated as described in the legend of Fig. 3. IL-6 secretion into the supernatants was analyzed after $24 \mathrm{~h}$ by sandwich-ELISA. Data represent means \pm SEM from six separate experiments performed in triplicates. IL-6 production of IL-1-treated cells was set as $100 \%$. * $\mathrm{p}<0.001$ compared to IL-1treated cells. IL- 6 release after incubation with the inhibitor alone was negligible and in the same range as the untreated controls.

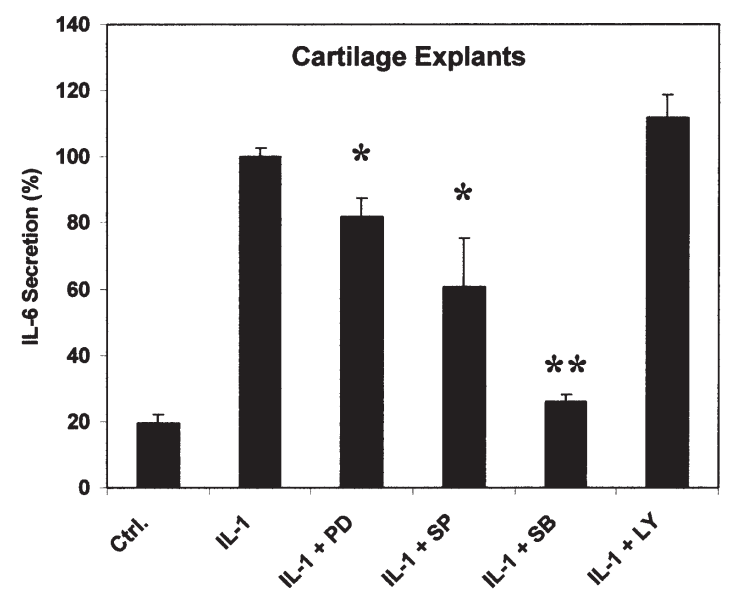

Figure 5. Effect of IL-1 on IL-6 production in human cartilage explants. Human cartilage from healthy donors was cut into $200 \mathrm{mg}$ slices and incubated in the presence or absence of IL-1 with or without distinct signaling inhibitors as mentioned above. IL-6 production was determined after $24 \mathrm{~h}$ by sandwich-ELISA. IL- 6 production of IL-1-treated explants was set as $100 \%$. Data represent means \pm SEM from seven separate experiments performed in triplicates. ${ }^{*} \mathrm{p}<0.05 ;{ }^{* *} \mathrm{p}<0.0001$ compared to IL-1-treated cells. IL-6 release after incubation with the inhibitor alone was in the same range as the untreated controls.

JNK by SP600125 and PI3K by LY294002 was without any effect. In contrast to the p38MAPK inhibitor SB203580, incubation of SW1353 with PD98059, SP600125 or LY294002 alone down-regulated the constitutive aggrecan mRNA expression. From these results we conclude that p38MAPK and ERK1/2 play crucial roles in the specific IL-1-mediated down-regulation of the aggrecan expression in SW1353.

Blockage of IL-1 effects. The aim of this study was to block specifically the IL-1-triggered pathways regulating the de-

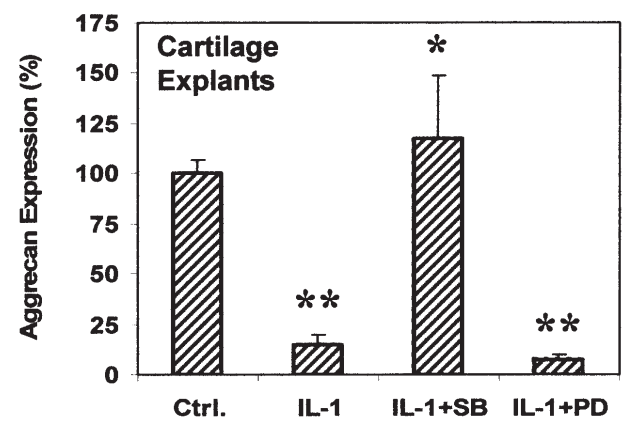

Figure 6. Inhibition of p38MAPK protects human cartilage from IL-1-induced down-regulation of aggrecan mRNA expression. Human cartilage explants from healthy donors were prepared and incubated with or without $10 \mathrm{U} / \mathrm{ml}$ rhIL- $1 \alpha$ in the presence or absence of $10 \mu \mathrm{M} \mathrm{SB} 203580$ (SB) and $10 \mu \mathrm{M}$ PD98059 (PD), respectively. Aggrecan mRNA expression was analyzed after $48 \mathrm{~h}$ by quantitative RT-PCR. Aggrecan expression of the untreated controls was set as $100 \%$. Data represent means \pm SEM from four separate experiments performed in triplicates. ${ }^{*} \mathrm{p}<0.05$ compared to IL-1-treated cells; ${ }^{* *} \mathrm{p}<0.0001$ compared to control.

differentiation of chondrocytes. We therefore treated SW1353 cells with distinct signaling inhibitors prior to IL-1 stimulation and analyzed IL-6 secretion into the supernatants, because IL-6 is supposed to act synergistically in the IL-1-induced suppression of proteoglycan synthesis (17). IL-1 strongly induced secretion of IL-6 by SW1353 cells thus confirming previous results (19). Only SB203580, the inhibitor of p38MAPK, as well as the PI3K inhibitor LY294002 were able to abolish induction of IL-6 (Fig. 4).

To analyze whether this inhibition is transferable to the ex vivo situation we performed the identical experiment using slices of human cartilage from seven healthy donors. As given in Fig. 5, we found a rapid and strong induction of IL-6 in explants of human cartilage within $24 \mathrm{~h}$ of incubation with IL-1 independent of the donor material. This cytokine secretion was completely blockable by SB203580 implying a critical contribution of the p38MAPK signaling pathway. Furthermore, the JNK inhibitor SP600125 was effective to a similar degree as it also blocked the IL-1-induced IL- 6 production by human cartilage explants. Minor effects were also seen in the presence of the ERK1/2 inhibitor, PD98059 (Fig. 5).

Analysis of regulation of aggrecan expression was performed by quantitative real-time PCR (Fig. 6). In 4 of 7 cases, human cartilage explants showed a massive down-regulation of the aggrecan mRNA expression after IL-1 stimulation. No alteration of the aggrecan mRNA expression was noted in the 3 other cases upon IL-1 exposure. Interestingly, IL-1-induced IL-6 production and its affection by signal transduction inhibitors did not differ between the responder and nonresponder group (data not shown). Apart from ERK1/2, we identified p38MAPK as playing a crucial role in mediating IL-1-induced down-regulation of aggrecan in SW1353 cells. We therefore analyzed a possible protective effect of the p38MAPK inhibitor SB203580 and the ERK1/2 inhibitor PD98059 in the responder group. As demonstrated in Fig. 6, IL-1 induced a massive down-regulation of the aggrecan expression to $12 \%$ of the untreated controls in human cartilage explants. This down-regulation was prevented by SB203580, whereas PD98059 had no effect. 


\section{Discussion}

The aim of this study was to identify the IL-1-triggered pathways regulating the dedifferentiation of chondrocytes. For these studies, the human chondrosarcoma cell line SW1353 and human cartilage explants were chosen. SW1353 cells have been used previously by our group as a reliable substitute for primary human chondrocytes regarding the study of IL-1-mediated protease and pro-inflammatory cytokine production and the signaling pathways involved (26). Initial expression studies with SW1353 cells and human primary chondrocytes revealed a constitutive expression of the pro-inflammatory constituents of the IL-1 receptor/ligand family. Expression of IL- $1 \alpha$ could not be detected in isolated primary chondrocytes from healthy donors, neither constitutively nor after stimulation with IL-1. The two structurally related cytokines, IL- $1 \alpha$ and IL-1ß, are agonists which induce identical responses by binding IL-1RI with high affinity (27). On the other hand, they differ remarkably with respect to regulation of gene expression, mRNA stability, translation, processing and secretion (28) which might be responsible for the differences in IL-1 $\alpha$ mRNA expression mentioned above. In order to gain insight into the signaling pathways involved in chondrocyte dedifferentiation, we used several pharmacological signal transduction inhibitors and analyzed their effect on the IL-1 response in human chondrocytes. We found a down-regulation of the chondrocyte differentiation marker aggrecan induced by IL- 1 . This observation is consistent with the results of previous studies indicating that IL-1 downregulates the major anabolic genes in articular chondrocytes including type II collagen and aggrecan (29-32). Inhibition of p38MAPK protected both, human chondrosarcoma cells and cartilage explants from IL-1-mediated down-regulation of aggrecan suggesting a pivotal role of this kinase in mediating the effects of IL-1 on anabolic gene expression in normal articular chondrocytes. Whereas inhibition of the ERK $1 / 2$ pathway was also effective in avoiding IL-1-induced downregulation of aggrecan in chondrosarcoma cells, this effect could not be observed in human cartilage indicating differences in the mechanism of IL-1-mediated effects on matrix molecules in chondrosarcoma cells and primary chondrocytes in the cartilage experiment. An interesting finding was that in contrast to p38MAPK inhibition by SB203580, inhibition of the PI3K and JNK pathway by LY294002 and SP600125, respectively, down-regulated the constitutive aggrecan expression in SW1353 cells suggesting a possible role of these signaling pathways in the homeostatic regulation of aggrecan expression but also preventing a conclusion with respect to an IL-1-specific component in these pathways. Although the ERK1/2 inhibitor PD98059 showed a minor suppressive effect on the constitutive aggrecan mRNA expression, it significantly counteracted IL-1-induced suppression indicating its participitation in the IL-1-specific effects.

We also analyzed the signaling pathways involved in IL-1-induced secretion of the pro-inflammatory cytokine IL-6 in human chondrocytes using the selected inhibitors. One of them, SB203580, functions as a selective inhibitor of p38MAPK only when used at low concentrations $(\leq 1 \mu \mathrm{M})$. In contrast, high concentrations of SB203580 (10-25 $\mu \mathrm{M})$ such as we have used inhibit both, p38MAPK and JNK (33). Since in our system the JNK inhibitor SP600125 did not exert any inhibitory effect on IL-1-induced IL-6 secretion by SW1353, while SB203580 was strongly effective, we conclude that this effect was mediated by p38MAPK inhibition. Pretreatment of SW1353 with LY294002 also blocked IL-1induced IL-6 secretion significantly. Under these conditions $(50 \mu \mathrm{M})$ it selectively abolishes PI3K activity without inhibiting other kinases including PKC and MAPK (34). The results were confirmed in ex vivo experiments. Human cartilage explants from healthy donors showed a suppression of IL-1induced IL-6 secretion after co-incubation with inhibitors of p38MAPK and JNK. These observations extend previous findings demonstrating a critical involvement of the ERK, p38MAPK, and NF- $\mathrm{B}$ pathway in IL-1B-mediated IL-6 mRNA expression in normal human articular chondrocytes (35). In contrast, our inhibitor studies in the human chondrosarcoma cell line SW1353 also demonstrated a role of PI3K in mediating IL-1-induced IL-6 secretion reflecting peculiarities of these tumor cells or influence of the microenvironment in cartilage. Taking into consideration the putative synergistical role of IL-6 in IL-1-induced suppression of proteoglycan synthesis in explants of human articular cartilage (17) and the suppressive effect of IL-6/sIL-6R complexes on the aggrecan core expression in isolated bovine articular chondrocytes (36), we hypothesize that chondrocyte dedifferentiation induced by IL-1 might also be mediated indirectly - at least in part - by IL-6 via the signaling pathways identified so far.

It has been shown previously that activation of the p38MAPK pathway induces markers of terminal chondrocyte differentiation not only in chondrocytes from different species (37) but also in human synovial fibroblasts (38). From these results we hypothesize that p38MAPK represents a critical signaling molecule mediating both, chondrogenic differentiation and dedifferentiation processes in articular cells. p38MAPK activity also modulates proliferation of rabbit articular chondrocytes under basal and IL-1-activated conditions (39). Apart from JNK, signal transduction via p38MAPK appears to represent the most important mechanism for the expression of IL-1-induced mediators $(13,14)$. Our own findings suggest a pivotal role for p38MAPK in mediating IL-1-induced down-regulation of the aggrecan gene expression in human chondrocytes. A recent publication reports on a protective effect of antagonists of IL-1 on the glycosaminoglycan content and aggrecan expression in cartilage explants from OA patients (40). According to our own results, these observations were found to be strictly donor-dependent.

The ability to block the IL-1 signaling cascade to enhance aggrecan expression in cartilage from certain donors is of interest in view of the demonstrated inhibitory effect of this cytokine on the synthesis of matrix molecules. From these data one can speculate that, at least in some cases, blockage of the IL-1 signaling pathway may have the potential to promote cartilage repair by inhibiting aggrecan degradation. The reason why some donor tissue did not respond to IL-1 with the expected down-regulation of the aggrecan expression remains to be elucidated. Gender-specific effects can most likely be excluded, since the cartilage used was exclusively gained from male corpses rendering the sample collective distinctly homogeneous. The contrasting responses might be 
due to differences in the activation status of the cartilage explants. Is has been shown previously that explantation and cutting of porcine articular cartilage activates intracellular inflammatory signaling pathways and induces IL-1 $\alpha$ mRNA expression (41). This might lead to a strong pre-stimulation with IL-1 abolishing certain further in vitro effects of the cytokine. As a result, cartilage may become hyporesponsive to catabolic factors such as IL-1 with respect to matrix molecule expression.

In conclusion, in the present study we identified a central role of p38MAPK in mediating IL-1-induced catabolic effects in human chondrocytes. The p38MAPK inhibitor SB203580 was found to antagonize IL-1-mediated downregulation of gene expression of the matrix molecule aggrecan. Although this effect is restricted to a certain donor collective, the identification and characterization of these signaling pathways might enable us to develop new modulation strategies for therapeutic use in inflammatory joint diseases. Interestingly, oral treatment with selective inhibitors of PI3K $\gamma$ was found to suppress joint inflammation and damage in mouse models of RA (42) rendering blockage of certain signal transduction pathways a promising tool as potential therapeutic intervention for the treatment of chronic inflammatory disorders.

\section{Acknowledgements}

This work was supported by an intramural grant (ReForM C) of the University of Regensburg. The technical assistance of Daniela Vogl and Carolin Guhr is gratefully acknowledged. J.R. was supported by multimmune $\mathrm{GmbH}$, Regensburg, Germany.

\section{References}

1. Dayer JM: The pivotal role of interleukin-1 in the clinical manifestations of rheumatoid arthritis. Rheumatology 42 (Suppl 2): ii3-ii10, 2003.

2. Goldring MB: Osteoarthritis and cartilage: the role of cytokines. Curr Rheumatol Rep 2: 459-465, 2000.

3. Van den Berg WB: Uncoupling of inflammatory and destructive mechanisms in arthritis. Semin Arthritis Rheum 30: 7-16, 2001.

4. Miossec P, Dinarello CA and Ziff M: Interleukin-1 lymphocyte chemotactic activity in rheumatoid arthritis synovial fluid. Arthritis Rheum 29: 461-470, 1986.

5. Greenfeder SA, Nunes P, Kwee L, Labow M, Chizzonite RA and $\mathrm{Ju}$ G: Molecular cloning and characterization of a second subunit of the interleukin 1 receptor complex. J Biol Chem 270: 13757-13765, 1995.

6. Korherr C, Hofmeister R, Wesche $\mathrm{H}$ and Falk W: A critical role for interleukin-1 receptor accessory protein in interleukin-1 signaling. Eur J Immunol 27: 262-267, 1997.

7. Radons J, Gabler S, Wesche H, Korherr C, Hofmeister R and Falk W: Identification of essential regions in the cytoplasmic tail of interleukin-1 receptor accessory protein critical for interleukin-1 signaling. J Biol Chem 277: 16456-16463, 2002.

8. Radons J, Dove S, Neumann D, Altmann R, Botzki A, Martin MU and Falk W: The IL-1 receptor accessory protein TIR domain: analysis of putative interaction sites by in vitro mutagenesis and molecular modeling. J Biol Chem 278: 49145-49153, 2003.

9. Colotta F, Dower SK, Sims JE and Mantovani A: The type II 'decoy' receptor: a novel regulatory pathway for interleukin 1. Immunol Today 15: 562-566, 1994.

10. Lang D, Knop J, Wesche H, Raffetseder U, Kurrle R, Boraschi D and Martin MU: The type II IL-1 receptor interacts with the IL-1 receptor accessory protein: a novel mechanism of regulation of IL-1 responsiveness. J Immunol 161: 6871-6877, 1998.

11. Guo F and Wu S: IRAK-2 and PI 3-kinase synergistically activate $\mathrm{NF}-\kappa \mathrm{B}$ and AP-1. Inflammation 24: 305-316, 2000.
12. O'Neill LA and Greene C: Signal transduction pathways activated by the IL-1 receptor family: ancient signaling machinery in mammals, insects, and plants. J Leukoc Biol 63: 650-657, 1998.

13. Mengshol JA, Vincenti MP and Brinckerhoff CE: IL-1 induces collagenase-3 (MMP-13) promoter activity in stably transfected chondrocytic cells: requirement for Runx-2 and activation by $\mathrm{p} 38$ MAPK and JNK pathways. Nucleic Acids Res 29: 4361-4372, 2001.

14. Vincenti MP and Brinckerhoff CE: The potential of signal transduction inhibitors for the treatment of arthritis: is it all just JNK? J Clin Invest 108: 181-183, 2001.

15. Bolton MC, Dudhia J and Bayliss MT: Quantification of aggrecan and link-protein mRNA in human articular cartilage of different ages by competitive reverse transcriptase-PCR. Biochem J 319: 489-498, 1996.

16. Schuerwegh AJ, Dombrecht EJ, Stevens WJ, van Offel JF, Bridts $\mathrm{CH}$ and De Clerck LS: Influence of pro-inflammatory (IL- $1 \alpha$, IL-6, TNF- $\alpha$, IFN- $\gamma$ ) and anti-inflammatory (IL-4) cytokines on chondrocyte function. Osteoarthritis Cartilage 11: 681-687, 2003.

17. Nietfeld JJ, Duits AJ, Tilanus MG, van den Bosch ME, Den Otter W, Capel PJ and Bijlsma JW: Antisense oligonucleotides, a novel tool for the control of cytokine effects on human cartilage. Focus on interleukins 1 and 6 and proteoglycan synthesis. Arthritis Rheum 37: 1357-1362, 1994.

18. Guerne PA, Carson DA and Lotz M: IL-6 production by human articular chondrocytes. Modulation of its synthesis by cytokines, growth factors, and hormones in vitro. J Immunol 144: 499-505, 1990 .

19. Shi J, Schmitt-Talbot E, Di Mattia DA and Dullea RG: The differential effects of IL- 1 and TNF- $\alpha$ on proinflammatory cytokine and matrix metalloproteinase expression in human chondrosarcoma cells. Inflamm Res 53: 377-389, 2004.

20. Vincenti MP and Brinckerhoff CE: Early response genes induced in chondrocytes stimulated with the inflammatory cytokine interleukin-1ß. Arthritis Res 3: 381-388, 2001.

21. Islam S, Kermode T, Sultana D, et al: Expression profile of protein tyrosine kinase genes in human osteoarthritis chondrocytes. Osteoarthritis Cartilage 9: 684-693, 2001.

22. Dower SK, Call SM, Gillis S and Urdal DL: Similarity between the interleukin 1 receptors on a murine T-lymphoma cell line and on a murine fibroblast cell line. Proc Natl Acad Sci USA 83: 1060-1064, 1986.

23. Goldring MB, Birkhead J, Sandell LJ, Kimura T and Krane SM: Interleukin 1 suppresses expression of cartilage-specific types II and IX collagens and increases types I and III collagens in human chondrocytes. J Clin Invest 82: 2026-2037, 1988.

24. Lefebvre V, Peeters-Joris C and Vaes G: Modulation by interleukin 1 and tumor necrosis factor $\alpha$ of production of collagenase, tissue inhibitor of metalloproteinases and collagen types in differentiated and dedifferentiated articular chondrocytes. Biochim Biophys Acta 1052: 366-378, 1990.

25. Kolettas E, Buluwela L, Bayliss MT and Muir HI: Expression of cartilage-specific molecules is retained on long-term culture of human articular chondrocytes. J Cell Sci 108: 1991-1999, 1995.

26. Radons J, Falk W and Schubert TEO: Interleukin-10 does not affect IL-1-induced interleukin-6 and metalloproteinase production in human chondrosarcoma cells, SW1353. Int J Mol Med 17: 377-383, 2006.

27. Born TL, Smith DE, Garka KE, Renshaw BR, Bertles JS and Sims JE: Identification and characterization of two members of a novel class of the interleukin-1 receptor (IL-1R) family. Delineation of a new class of IL-1R-related proteins based on signaling. J Biol Chem 275: 29946-29954, 2000.

28. Dinarello CA: Biologic basis for interleukin-1 in disease. Blood 87: 2095-2147, 1996.

29. Aigner T, McKenna L, Zien A, Fan Z, Gebhard PM and Zimmer R: Gene expression profiling of serum- and interleukin13-stimulated primary human adult articular chondrocytes - a molecular analysis based on chondrocytes isolated from one donor. Cytokine 31: 227-240, 2005.

30. Fan Z, Bau B, Yang H, Soeder S and Aigner T: Freshly isolated osteoarthritic chondrocytes are catabolically more active than normal chondrocytes, but less responsive to catabolic stimulation with interleukin-1ß. Arthritis Rheum 52: 136-143, 2005.

31. Ganu VS, Hu SI, Melton R, Winter C, Goldberg VM, Haqqi TM and Malemud CJ: Biochemical and molecular characterization of stromelysin synthesized by human osteoarthritic chondrocytes stimulated with recombinant human interleukin-1. Clin Exp Rheumatol 12: 489-496, 1994. 
32. Prehm P: Inhibitors of hyaluronan export prevent proteoglycan loss from osteoarthritic cartilage. J Rheumatol 32: 690-696, 2005.

33. Dolfi F, Garcia-Guzman M, Ojaniemi M, Nakamura H, Matsuda $\mathrm{M}$ and Vuori K: The adaptor protein Crk connects multiple cellular stimuli to the JNK signaling pathway. Proc Natl Acad Sci USA 95: 15394-15399, 1998.

34. Vlahos CJ, Matter WF, Hui KY and Brown RF: A specific inhibitor of phosphatidylinositol 3-kinase, 2-(4-morpholinyl)-8phenyl-4H-1-benzopyran-4-one (LY294002). J Biol Chem 269: 5241-5248, 1994.

35. Fan Z, Bau B, Yang H and Aigner T: IL-1ß induction of IL-6 and LIF in normal articular human chondrocytes involves the ERK, p38 and NF-кB signaling pathways. Cytokine 28: 17-24, 2004.

36. Legendre F, Dudhia J, Pujol JP and Bogdanowicz P: JAK/STAT but not ERK1/ERK2 pathway mediates interleukin (IL)-6/ soluble IL-6R down-regulation of type II collagen, aggrecan core, and link protein transcription in articular chondrocytes. Association with a down-regulation of SOX9 expression. J Biol Chem 278: 2903-2912, 2003.
37. Yosimichi G, Nakanishi T, Nishida T, Hattori T, TakanoYamamoto $\mathrm{T}$ and Takigawa M: CTGF/Hcs24 induces chondrocyte differentiation through a p38 mitogen-activated protein kinase (p38MAPK), and proliferation through a p44/42 MAPK/ extracellular-signal regulated kinase (ERK). Eur J Biochem 268: 6058-6065, 2001.

38. Seto H, Kamekura S, Miura T, et al: Distinct roles of Smad pathways and p38 pathways in cartilage-specific gene expression in synovial fibroblasts. J Clin Invest 113: 718-726, 2004.

39. Studer RK, Bergman R, Stubbs T and Decker K: Chondrocyte response to growth factors is modulated by $\mathrm{p} 38$ mitogen-activated protein kinase inhibition. Arthritis Res Ther 6: R56-R64, 2004.

40. Kobayashi M, Squires GR, Mousa A, et al: Role of interleukin-1 and tumor necrosis factor $\alpha$ in matrix degradation of human osteoarthritic cartilage. Arthritis Rheum 52: 128-135, 2005.

41. Gruber J, Vincent TL, Hermansson M, Bolton M, Wait R and Saklatvala J: Induction of interleukin-1 in articular cartilage by explantation and cutting. Arthritis Rheum 50: 2539-2546, 2004.

42. Camps M, Ruckle T, Ji H, et al: Blockade of PI3K $\gamma$ suppresses joint inflammation and damage in mouse models of rheumatoid arthritis. Nat Med 11: 936-943, 2005. 